\title{
LA HERMENÉUTICA TRANSCULTURAL. LA INTERPRETACIÓN NIETZSCHEANA DE LAS RELIGIONES Y CULTURAS EXTRAEUROPEAS
}

Transcultural hermeneutics.

Nietzsche's interpretation of the extra-European religions and cultures

\author{
Johann Figl \\ Universidad de Viena
}

RESUMEN: En mi artículo quisiera explicar, en primer lugar, algunos ejemplos de los conocimientos tempranos de Nietzsche sobre culturas y religiones extraeuropeas y la metodología histórico-genealógica, estrechamente relacionada con ellas, para centrarme, en segundo lugar, en la "época de la comparación», como una de sus consecuencias. En tercer lugar presentaré sus consecuencias para la concepción del ser humano aplicada por Nietzsche, para analizar, en cuarto y último lugar, la relación entre la nueva hermenéutica filosófica y la transculturalidad de Nietzsche.

Palabras clave: hermenéutica - transculturalidad - metodología genealógica

ABSTRACT: In this article I wanted to explain, in the first place, some examples of Nietzsche's early knowledge on extra European cultures and religions and on the historicalgenealogical methodology, closely related to them. Secondly, I will center in «the time of comparison" as one of its consequences. Thirdly, I will present its consequences for Nietzsche's conception of human being, for, in quarter and last place, to analyze the relation between the new philosophical hermeneutics and Nietzsche's transculturality.

Keywords: Hermeneutics - Transculturality - Genealogical Methodology

\section{NIETZSCHE Y LAS CULTURAS Y RELIGIONES EXTRAEUROPEAS}

\section{a) Ejemplos de los primeros y tempranos conocimientos de Nietzsche en su formación académica}

El presente artículo tiene como punto de partida la trayectoria académica y científica de Nietzsche, desde sus tiempos de estudiante hasta su época de catedrático. A través de este acercamiento desde una perspectiva pedagógico-didáctica, podemos observar claramente hasta qué punto se refleja en la formación académica específica de Nietzsche la manera general y ampliamente difundida de tratar a las religiones y culturas «desconocidas», característica de la Europa de mediados del siglo XIX. Dichas religiones y culturas se percibían como «razas» diferentes, según la terminología de la época, desde una perspectiva eurocéntrica. Vemos cómo en los libros de texto (por ejemplo de geografía), utilizados en las escuelas de enseñanza secundaria frecuentadas por Nietzsche, se encontraban contenidos manifiestamente racistas, pero, al mismo tiempo, también podemos observar cómo los prejuicios, muy extendidos en aquella época, frente a las religiones no cristianas y a las culturas extraeuropeas se fueron desvaneciendo, gracias a la alta 
cualificación filológica de los profesores y a los estudios históricos realizados, es decir, las bases de la hermenéutica científica del siglo XIX. Vemos también cómo, por ejemplo, a través de la filología indogermánica y de palabras paradigmáticas procedentes del sánscrito, se pudo tender un puente histórico-lingüístico hacia las culturas y religiones de la India, acercando a los pueblos entre sí, y cómo se relativizaban, debido a los nuevos estudios de la época sobre Mahoma y el islam, los conceptos discriminatorios acerca de esa religión.

Mediante esta presentación no se pretende ofrecer únicamente una aportación a la hermenéutica de las culturas y religiones extraeuropeas, basándose en uno de los filósofos más importantes de la Epoca Moderna, sino que se quiere presentar, a la vez, ideas elementales acerca de la tematización del «extraño» en aquella cultura europea que sirvió a Nietzsche de punto de partida para poder llegar, paso a paso, a una visión transcultural relativizadora, es decir, a una visión «transeuropea».

Quisiera señalar tres ejemplos:

1. el mundo de los «salvajes», como se decía en aquel entonces;

2. el primer contacto con el zoroastrismo;

3. la percepción del islam.

1. Las «rudas» costumbres de «pueblos salvajes».

El libro de historia utilizado en la escuela media que frecuentó Nietzsche antes de ingresar en la elitista escuela de Naumburg (Schulpforta), llevaba el título de Libro de la Historia Universal. Este libro se encuentra aún hoy en la biblioteca de Nietzsche en Weimar.

En ese mismo contexto de historia universal en que se impartían las clases de historia, se interpretaba la forma de vida de las culturas indígenas aún existentes: "Incluso en la actualidad, algunos pueblos salvajes siguen consumiendo crudos los animales cazados», señalando que esos vestigios de una cultura de cazadores aún se podían encontrar en otros continentes fuera de Europa: «El incremento paulatino del salvajismo, que aún se puede encontrar en los demás continentes, es la consecuencia lógica de ese modo de vida» ${ }^{1}$.

Dicho salvajismo es documentado a través de algunos ejemplos etnográficos como, por ejemplo, la desnudez de los «negros» (sic) de la costa oriental de Australia, que se pintan con arcilla roja. Así es como se describe la pintura corporal de los aborígenes, eso sí, sin utilizar ese término. De forma más clara se manifiesta ese salvajismo, expresado en las crueles costumbres, en una redacción elaborada por Nietzsche sobre ese mismo tema tres años más tarde en la escuela media Schulpforta ${ }^{2}$. En general, podemos constatar una visión discriminatoria hacia los pueblos denominados «primitivos».

\section{El contacto con los persas y Zaratustra.}

El libro de historia de Welter contiene un capítulo dedicado a Ciro y a «la historia de su juventud» (ese último título posiblemente haya servido de orientación a Nietzsche a la hora de titular su poema La juventud de Ciro). En su descripción preliminar, los persas son retratados como «guerreros y amantes de

1. Th. B. Welter, Lehrbuch der Weltgeschichte, 1854 (BN = Biblioteca de Nietzsche), p. 28.

2. Cf. ibid., pp. 59 ss. 
la libertad», que viven en parte como nómadas y en parte en asentamientos fijos. Su religión se describe de la siguiente manera:

Veneran a sus dioses de la misma manera que los antiguos germanos, sin estelas, templos ni altares, adorando además a los astros celestes, al fuego, de forma especial. Sus sacerdotes realizaban las ofrendas en lo alto de las montañas y se llamaban magos. Su líder y el verdadero fundador de su fe fue un sabio que vivía, aproximadamente seiscientos años antes de Cristo, en el interior de Asia, llamado Zoroāster o Zerduscht ${ }^{3}$.

Zerduscht es el nombre de Zaratustra en el avesta, Zoroāster es su denominación griega.

Su teoría se explica de la siguiente manera:

Su teoría se caracteriza, en especial, por el hecho de que, además del creador supremo del mundo, al que llamaba Ormuz, existía otro ser divino, Ariman, el creador del mal en el mundo, así como varios ángeles, unos buenos y otros malos, subordinados a los primeros ${ }^{4}$.

Asimismo se menciona el Zendavesta (aunque en la actualidad se habla tan sólo de Avesta $)^{5}$, al igual que la permanencia de ese culto entre los parsas.

Mucho antes de reproducir, en su obra Asi habló Zaratustra, la descripción de Zaratustra, ofrecida en la obra Kulturgeschichte [Historia de la cultura] de Hellwald en 1881, Nietzsche tuvo conocimiento, por varias fuentes, de los famosos relatos sobre ese fundador de la religión. Por supuesto, al principio y durante su época de estudiante sus intereses fueron distintos a los que tenía en el momento de concebir su gran obra.

3. El islam.

Posiblemente, durante su estancia en la escuela media Schulpforta, Nietzsche abordara, de forma literaria, temas relacionados con el islam.

Un manuscrito de Nietzsche, redactado en sus tiempos de bachiller, que hasta la fecha no ha sido publicado, demuestra además que ya había adquirido, en la escuela media Schulpforta, unos conocimientos fundamentales sobre Mahoma, el islam, sus corrientes y su primera expansión. Esos conocimientos eran, en gran medida, una reproducción de las informaciones disponibles, en aquel entonces y gracias a las obras redactadas en esa época, sobre el profeta y la religión fundada por él. Las opiniones formuladas acerca de Mahoma, que en la historia del Occidente cristiano eran, en gran medida, discriminatorias, al igual que las opiniones vertidas sobre la religión islámica ${ }^{6}$, se verán relativizadas, al menos parcialmente, tanto en obras contemporáneas (en especial, de Washington Irving) a las que tendrá acceso Nietzsche, como a través de análisis críticos de la historia

3. Ibid., p. 5 .

4. Ibid.

5. El origen etimológico sigue siendo incierto; probablemente avesta signifique «glorificación» o «conocimientos (religiosos)»: cf. "Avesta», en Religion in Geschichte und Gegenwart, 4. ${ }^{a}$ ed., vol. 1, p. 1024.

6. Cf. H. Bobzin, Mohammed, München: Beck, 2000, pp. 9 ss.: «Vom 'Pseudopropheten’ zum 'Helden': Abendländische Mohammedbilder». 
(por ejemplo, una comparación entre el Corán y las epopeyas de Homero), que abrieron el camino hacia un estudio más objetivo del islam. Desde el punto de vista actual podemos constatar que Nietzsche supo describir, en gran medida correctamente, los principios elementales de la fe islámica. Durante su época de estudiante en la escuela media y, más tarde, en la universidad, y también como catedrático de Filología Clásica en la universidad, Nietzsche se vio confrontado con numerosas opiniones sobre culturas extraeuropeas, que conocía, en su mayoría, en el contexto de los métodos histórico-críticos y comparativos. Asimismo conocía los principios de la ciencia de la religión, una ciencia que comenzaba a desarrollarse en la época. A continuación me gustaría presentar los principios científico-metódicos de la época, ya que marcaron también las estructuras de la posterior hermenéutica filosófica de Nietzsche.

\section{b) La metodología histórico-genealógica}

Puede que Nietzsche se topara con el término genealogía en las clases de lengua que su profesor Koberstein impartía en la escuela media Schulpforta, un término que, a su vez, se vio fuertemente influenciado por la interpretación genealógica del lenguaje ofrecida por Grimm ${ }^{7}$, con el que mantenía una buena amistad. Así mismo, para Max Müller, el fundador de la ciencia de la religión, fueron fundamentales la búsqueda de los orígenes y las deducciones genealógicas a la hora de demostrar que «era posible establecer una clasificación genealógica, paralela a la de los idiomas, de las religiones ${ }^{8}$. La lingüística comparativa nos lleva a la «protohistoria de la humanidad, en especial, de los pueblos indígenas», como consta en una enciclopedia del siglo XIX ${ }^{9}$.

Nietzsche ha extendido el pensamiento genealógico más allá de los contextos clásico e indogermánico, abarcando en el mismo la «protohistoria» y el mundo de los «salvajes». Las redacciones elaboradas durante su época de estudiante de bachillerato como, por ejemplo, sobre Ermanarico, ya giraban en torno a la «protohistoria» (de los godos).

La lectura, durante su época de catedrático, de las obras de Tylor y Lubbock, con sus retratos de pueblos indígenas, ofrece a Nietzsche una visión relativamente global de la «protocultura», es decir, de la «protohistoria» de la humanidad. Una vez más, se deja guiar por la «fascinación por los orígenes» ${ }^{10}$.

Nietzsche aplicó, en sus tratados filosóficos, el método del pensamiento resultante de la filología, y más tarde también de la etnología (en lo relativo a los temas del estudio de las religiones y otros temas culturales) a problemas antropológicos en general, como se puede observar en Humano, demasiado humano;

7. Cf. K. A. Koberstein, Grundriß der Geschichte der deutschen Nationalliteratur, $5 .^{a}$ ed., vol. 1, 1872, 13: «Genealogie der Gothen», así como la nota 4: «Genealogien der altsächsischen Stammsagen».

8. M. Müller, Einleitung in die vergleichende Religionswissenschaft, $2 .^{a}$ ed. 1876, Vorrede III, cf. pp. 95 ss.

9. «Urgeschichte», en Meyers Konv.-Lexikon 15, 180. Véase asimismo el Sprachenstammbaum de Schleicher, que conduce a la «indogermanische(n) Ursprache»: KGW II/2 194.

10. Cf. D. S. Thatcher, "Nietzsche's Debit to Lubbock»: Journal of the History of Ideas 44 (1983), 293-309; p. 293, nota 1: «fascination with beginnings», en la que se introdujeron también numerosos títulos de la Bibliothek Nietzsches que hacen referencia a Ursprung y Urgeschichte. 
una obra que, según la interpretación del propio Nietzsche, anticipa el principio de La genealogía de la moral.

Ese pensamiento del origen es para Nietzsche una condición previa para su hermenéutica transcultural, ya que permite deducir determinadas figuras del ethos, de la religión, del dominio, etc., partiendo de una «forma originaria» (imaginaria) que, a menudo, entra en oposición con la (auto)comprensión «cultural». Como nivel de argumentación adicional se puede añadir la perspectiva comparativa, ya que conduce igualmente a los orígenes.

\section{2. «LA ÉPOCA DE LA COMPARACIÓN» - UNA CONSECUENCIA DEL PENSAMIENTO HISTÓRICO}

En una nota destacable que Nietzsche apuntó en 1887/1888 en el contexto de sus anotaciones para El Anticristo, constata:

Nuestra ventaja: vivimos en la época de la comparación, podemos establecer mejores retrospectivas que nunca: somos la conciencia de la historia en general [...] Sabemos disfrutar de otra manera, sufrimos de otra manera: la comparación de una inmensa cantidad de múltiplos es nuestra actividad más instintiva (KGW VIII/2 409: $11[374])^{11}$.

Esa mentalidad de la comparación es el resultado del pensamiento histórico practicado en el siglo XIX. En un estilo casi hegeliano sentencia Nietzsche, el gran crítico del idealismo, que «nosotros» somos «la conciencia de la historia en general». Una conciencia marcada por la historia es, por lo tanto, la que nos permite establecer comparaciones. La "genealogía» («historia») y el «comparatismo» se condicionan mutuamente, puesto que son sobre todo las ciencias comparativas las que definen, de modo inverso, la génesis, por ejemplo de los idiomas, de las culturas y de las religiones.

Sabemos que Max Müller es considerado el fundador de la ciencia de la religión por el hecho de haber trasladado el método comparativo, utilizado en la lingüística, a la ciencia de la religión. Aspiraba a crear una ciencia de la religión en paralelo y siguiendo el ejemplo de la lingüística comparativa, de forma que se estableciera una ciencia comparativa de la religión.

La exigencia de comparación, formulada por Müller a finales de los años sesenta del siglo XIX, fue desarrollada por Nietzsche (que, por cierto, poseía dichos «ensayos»), aunque por supuesto en un sentido distinto al asumido por Max Müller.

Nietzsche esbozó, ya en 1875 , tales comparaciones, probablemente en relación con un proyecto de «Consideraciones intempestivas» sobre la religión ${ }^{12}$. Prueba de ello es una anotación según la cual «cada religión [...] [cuenta] para

11. A este término de Nietzsche remite W. Halbfass en el capítulo «India and the Comparative Method», en India and Europe, Albany: State University of New York Press, 1988, p. 430. No obstante, el título del aforismo n. ${ }^{\circ} 23$ de Humano, demasiado humano I es «Época de la comparación»;

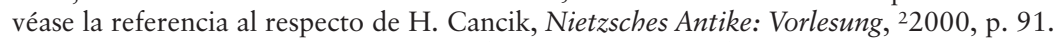

12. Cf. KGW IV/1 85 s.: 1[3-4]; además KGW IV/ 4 Nb. 357. 
sus imágenes supremas con una analogía en un estado del alma» (KGW IV/1 104: $3[53])^{13}$.

En ese contexto, se comparan tres religiones (Grecia antigua/cristianismo/ islam) en cuanto a su definición del "amor", como uno de los términos fundamentales que, en gran medida, se encontraban en la literatura de la época ${ }^{14}$. La comparación entre el islam y el cristianismo sigue preocupando a Nietzsche en obras posteriores ${ }^{15}$. No obstante, tenía un mayor interés por la comparación entre el budismo y el cristianismo, o entre las culturas de características india y cristiana $^{16}$. En El Anticristo ofrece una destacada comparación entre el budismo y el cristianismo, definiéndolas como las dos religiones "nihilistas» que sin embargo, según Nietzsche, revelan unas diferencias significativas (cf. AC $\$ \$ \$ 20-23$, KGW VI/3, especialmente 184 ss.). Hemos de situar en ese contexto la anotación anteriormente citada, procedente de las obras tardías sobre «la época de la comparación».

Los principios metodológicos de la historia o genealogía y de la comparación determinan las críticas tardías de Nietzsche al cristianismo, al igual que su apelación a la «neutralidad» y a la «disciplina del espíritu». La intención de Nietzsche consistía en ofrecer, mediante esos métodos, definidos ya como filosóficos, el análisis de una cultura o religión (el cristianismo) a través de la comparación con otras religiones o culturas (en especial, el budismo, pero también la cultura de la Antigüedad y el islam):

El cristianismo nos arrebató la cosecha de la cultura antigua, más tarde volvió a arrebatarnos la cosecha de la cultura islámica. El prodigioso mundo de la cultura mora de España, que en el fondo es más afín a nosotros que Roma y que Grecia, que habla a nuestro sentido y a nuestro gusto con más fuerza que aquéllas, fue pisoteado - no digo por qué pies - ¿por qué?, porque debía su génesis a unos instintos aristocráticos, a unos instintos varoniles, porque decía sí a la vida (AC $\mathbb{S} 60$, p. 247$)^{17}$.

Nietzsche sigue considerándose, incluso en sus últimas obras, como "filólogo», lo que explica su intención de conservar la neutralidad. No obstante, a la vez se ve en la función del «médico» (cf. AC \$47, p. 224), lo que le lleva a tomar partido en contra del cristianismo y de movimientos similares. En ambas dimensiones aspira a superar la cultura europea o la religión cristiana mediante una nueva concepción del ser humano y del Estado, así como a través de una nueva forma del ser.

13. Cf. especialmente KGW IV/1 163 s.: 5[166]: «Über Religion»; además KGW/IV 4, Nb. 364.

14. Cf. S. Hardiyanto, Zwischen Phantasie und Wirklichkeit. Der Islam im Spiegel des deutschen Denkens im 19. Jahrhundert, Frankfurt a. M. et al.: Peter Lang, 1992; sobre Nietzsche, especialmente pp. 161-176.

15. Durante sus últimos años de actividad intelectual, Nietzsche adquirió una obra de J. Wellhausen: Skizzen und Vorarbeiten. Drittes Heft: Reste arabischen Heidenthums (1887), que resultó significativa para sus conocimientos de lo islámico y preislámico. De esa obra cita una serie de extractos: cf. KGW VIII/2 354 ss.: 11[287-293] y otros, cf. S. Hardiyanto, op. cit., pp. 170 ss.

16. Cf. J. Figl «Nietzsche's Encounter with Buddhism», en B. Bäumer y J. R. Dupuche (eds.), Void and Fullness in the Buddhist, Hindu and Christian Traditions. Śunya - Pürna - Plêroma. With a Concluding Speech by His Holiness the Dalai Lama, New Delhi: D. K. Printworld, 2005, pp. 225-237; cf. el aforismo 96 "In hoc signo vinces», en Aurora (KGW V/1 83 s.).

17. AC, ed. de A. Sánchez Pascual, Madrid: Alianza, 2006, p. 117. 
Con todo ello llega a adoptar una visión que, de forma especialmente acentuada, somete a un análisis crítico también a la «propia» cultura y religión. En ese sentido, aplica los principios de un análisis filosófico que, aunque orientándose en cierta manera a los métodos utilizados en las ciencias históricas y comparativas de la época, llega a generalizar los principios de dichas ciencias (como son la objetividad, la historicidad y el comparatismo $)^{18}$, transfiriéndolos a un contexto antropológico general. En esa nueva hermenéutica, los conocimientos comparativos y sobre la historia de la religión van adquiriendo una nueva función, cosa que podemos observar hasta en sus últimas obras. Los conocimientos sobre culturas y religiones extraeuropeas sirven de base para la concepción de una antropología que no sólo cuestiona la tradición europea de valores, sino que aspira, finalmente, a una concepción del ser humano y de la sociedad que pueda considerarse como transcultural, también en el sentido de que se debe superar la historia de las culturas (incluida la de sus religiones), existente hasta ese momento. Con esas intenciones, Nietzsche había dejado atrás la metodología científica como tal. No obstante, su pensamiento está marcado, a partir de entonces, por una hermenéutica intercultural en forma de una genealogía filosófica y de un análisis crítico-comparativo de las religiones y culturas. Ese horizonte transcultural, que se ha ido desarrollando, paso a paso, desde los primeros años de la formación académica de Nietzsche, puede considerarse, con razón, como una de las características fundamentales de la filosofía de Nietzsche que, a su vez, se encuentra en el centro y, al mismo tiempo, al margen de la cultura europea.

\section{LAS CONSECUENCIAS PARA LA CONCEPCIÓN DE LA PERSONA}

En lo que respecta a la concepción de la persona (Menschenbild), Nietzsche, que proviene de un entorno marcadamente cristiano-burgués, llega, a través del ideal clásico de la humanidad, determinante en sus estudios universitarios, a los aspectos arcaicos de la existencia del ser humano, considerados como «prehistóricos» y ligados a la crueldad e irracionalidad. El pensamiento «impuro» (sic) de las culturas preclásicas le sirve de base para interpretar, finalmente, la cultura clásica de los griegos. En cuanto a su opinión acerca de la religión, dominan, a este nivel, especialmente los aspectos mágicos y animistas. Con esta acentuación, el enfoque de Nietzsche difiere del resto de los conceptos contemporáneos que, a su vez, continuando en la línea de la tradición de la ilustración burguesa del siglo XIX, aspiraban a una antropología general que abarcara todas las culturas, pero que interpretaba lo "humano», en su sentido histórico y comparativo, partiendo de un ideal de la humanidad que se correspondía, en el fondo, con el de su profesor en Leipzig, Georg Curtius, el fundador de la lingüística com-

18. En una serie de casos, sin embargo, esta historicidad y objetividad no vino de facto alcanzada, por ejemplo con respecto al entendimiento del «Libro de la ley de Manu» (cf. AC $\$ 56, \mathrm{KGW}$ VI/3 237 s.): véase el análisis de A. Etter, «Nietzsche und das Gesetzbuch des Manu»: NietzscheStudien 16 (1987), 340-352, que al respecto señala cómo Nietzsche se refiere a la representación, poco fiable desde el aspecto indológico, de L. Jacolliot: Les législateurs religieux. Manou, Moïse, Mahomet, 1876 (BN); cf. G. Campioni et al. (eds.), Nietzsches persönliche Bibliothek, Berlin: Walter de Gruyter, 2003, p. 318. 
parativa, con influencias, además, de Max Müller. Dicha interpretación se ve reflejada, por ejemplo, en escritos que Nietzsche menciona en sus anotaciones para la Enciclopedia de la Filología clásica, como el escrito «Sobre la historia y la misión de la filología». Nietzsche conocía esos principios pero, basándose en los conocimientos existentes sobre la historia de la cultura y de la religión, llega a una comprensión distinta, en gran parte contraria, de lo «humano» y de lo «demasiado humano». De los enormes y cada vez mayores conocimientos sobre las diferentes culturas (incluidos los pueblos indígenas) que en el siglo XIX se encontraban al alcance de la educación y ciencia, Nietzsche extrae nuevas y amplias conclusiones: en ese contexto plural, «transeuropeo», la religión y las costumbres de la «propia» cultura ya no aparecen sólo en su relatividad y condicionalidad histórica, sino que se "descubren", al mismo tiempo, sus reveses «arcaicos», «rudos», es decir, aquellos aspectos de los que no tenían conciencia la burguesía culta ni la opinión pública del siglo XIX, o cuya naturaleza brutal y cruel ignoraban (por ejemplo, de la Antigüedad griega) o no percibían como posibilidades o realidades humanas. Uno de los objetivos de la hermenéutica crítica transcultural de Nietzsche consistía en hacer visibles con toda claridad aquellos aspectos inconscientes y aquella realidad, en gran parte reprimida. Otro objetivo era hacer justicia a las diferentes culturas, una reivindicación que Nietzsche dirigía a algunos de sus coetáneos. Dicho objetivo se formula en una época en la que Nietzsche escribe con frecuencia citas filológicas en sus publicaciones filosóficas, especialmente en el caso de Humano, demasiado humano.

En la trayectoria de Nietzsche, las bases para la transmisión de conocimientos sobre el estudio de las religiones se fundamentan principalmente en la metodología histórica y comparativa aplicada a mediados del siglo XIX. En consecuencia, tanto desde el punto de vista de los contenidos, como desde el punto de vista metodológico, se estaban creando, tanto en sus tiempos de estudiante como en su época docente, unos fundamentos que, a la vez, suponían la base del pensamiento transcultural en sus obras filosóficas, empezando por aquellos escritos que redactaba en sus tiempos de catedrático de Filología Clásica (como El nacimiento de la tragedia, las Consideraciones intempestivas y Humano, demasiado humano), hasta llegar a sus obras tardías (como Más allá del bien y del mal, La genealogía de la moral, El anticristo ${ }^{19}$.

\section{PERSPECTIVAS TRANSCULTURALES DE UNA FILOSOFÍA CRÍTICA FRENTE A LA CIENCIA, ES DECIR, DE LA FILOSOFÍA «HERMENÉUTICA» DE NIETZSCHE}

Para poder apreciar debidamente los conocimientos de Nietzsche sobre las culturas y religiones de la antigua Europa y extraeuropeas, así como sus valoraciones de las mismas, resulta necesario, desde mi punto de vista, señalar, además de la importancia fundamental de su formación filológico-científica, las fuertes críticas vertidas sobre la cultura científica del siglo XIX. Hemos de tomar en consideración especialmente la dimensión crítica frente a la ciencia (wissenschaftskritisch) que se hace patente en sus opiniones filosóficas sobre culturas y religiones

19. Algunas de esas conexiones ya fueron mencionadas por mí en publicaciones anteriores. 
«extrañas». Su trayectoria académica, cuyo rumbo quedó establecido con su lección inaugural como catedrático de Filología (Basilea, 1869), dedicada al tema de «Homero y la filología clásica», le llevó de la filología a la filosofía. Su «ambición» como filólogo la resume finalmente de la «manera más personal», como él mismo dice, "en la fórmula reducida de un credo", invirtiendo el sentido de una frase de Séneca: “"philosophia facta est quae philologia fuit"»" (KGW II/1 268).

Según Nietzsche, «se ha de expresar que todas y cada una de la actividades filológicas deben estar encerradas y englobadas en una cosmovisión filosófica, en la que el individuo y lo individualizado se evaporarán como algo reprobable y en la que sólo permanecerán el todo y lo uniforme» (KGW II/1 268 s.).

Esa «concepción de uniformidad» y el consiguiente distanciamiento tendencial y el cuestionamiento, en parte, de la filología clásica, se hacen más patentes en El nacimiento de la tragedia, al igual que en las críticas al método histórico, recogidas en las Consideraciones intempestivas y en Sobre la utilidad y el perjuicio de la historia para la vida. En Schopenhauer como educador, Nietzsche persigue el objetivo de "visualizar el panorama general de la vida y de la existencia», es decir, de comprender la «visión global», la conexión. En las clases impartidas por Nietzsche se puede encontrar, asimismo, una serie de referencias a una «filosofización de la filología» ${ }^{21}$.

La orientación filosófico-hermenéutica en el manejo de textos se pone de manifiesto, más adelante, en los escritos no filológicos de Nietzsche, sobre todo en lo que se refiere a la acentuación de la dimensión vital. La filología y los conocimientos sobre la historia de la religión se han puesto, de forma general y como se ha podido constatar en cuanto a las religiones y filosofías orientales, al servicio de las preocupaciones y reflexiones existenciales. No se trata de una comprensión "objetiva»y, por tanto, «exterior», sino de un acercamiento «interior», como lo experimentó, a juicio de Nietzsche, por ejemplo Paul Deussen, que fue «el primer europeo» «capaz de acercarse a la filosofía india desde dentro». El «ejemplo» de Deussen demuestra, asimismo, que Nietzsche no menospreciaba en absoluto esa forma de acercamiento filológico-científico (siendo muestra de ello la obra del mencionado indólogo). Lo importante y decisivo para él era el hecho de que se destacara la dimensión existencial en el estudio de textos de otras culturas. Para conseguirlo, hemos de percibir, según Nietzsche, un ejemplo vivo a través del texto, como él mismo experimentó en relación con Schopenhauer. En sus obras tardías, los términos de «filología» y «texto» se convierten en metáforas de los fenómenos de la vida (como, por ejemplo, los estados psíquicos), hablándose, además, del «texto básico» de la religión ${ }^{22}$.

Asimismo, Nietzsche busca una dimensión que fomente la vida y que le otorgue un nuevo significado. En El nacimiento de la tragedia, esa fuente que hace posible la vida es la experiencia griega del mundo, a la que considera como «la

20. La frase original de Séneca es: «itaque quae philosophia fuit, facta philologia est» (Epistula 108, 23), cita de BAW 5, Nb. 479.

21. Cf. F. Bornmann, «Anekdota Nietzscheana aus dem philologischen Nachlaß der Basler Jahre (1869-1878)», en T. Borsche y otros (eds.), 'Centauren-Geburten'. Wissenschaft, Kunst und Philosophie beim jungen Nietzsche, Berlin: Walter de Gruyter, 1994, p. 74.

22. Cf. J. Figl, Dialektik der Gewalt, Berlin: W. de Gruyter, 1984, especialmente pp. 244 ss., 278 ss. passim. 
única y más profunda posibilidad de vida». Con ese horizonte, se dedica al estudio de textos sobre culturas extraeuropeas, como, por ejemplo, las descripciones de Koeppen sobre la fiesta budista del comienzo de la primavera. A pesar de que esa religión le pareciera a Nietzsche en aquel entonces (siguiendo a Schopenhauer, pero también a Schaarschmidt, a cuya clase sobre la historia de la filosofía asistió en la Universidad de Bonn) una religión caracterizada por el «anhelo de la nada» y el «quietismo», se muestra sorprendido de los elementos dionisíacos y extáticos que contiene. Se trata, en su opinión, de aspectos positivos, que hacen posible la vida.

Posteriormente, en la trayectoria intelectual de Nietzsche ya no se trataría, en primer lugar, del estudio científico de las culturas, ni tampoco de la definición de teorías del estudio de las religiones que, a su vez, requerirían de una argumentación filológica e histórica, sino de la búsqueda y de la explicación de su propia filosofía, de una hermenéutica de la vida, de la que se deducen valoraciones críticas y, en parte, también afirmativas de las religiones. En reiteradas ocasiones se comparan, en ese contexto, los elementos del hinduismo (Nietzsche hablaba del brahmanismo), del budismo y del islam con los aspectos análogos del cristianismo, dándoles una valoración más positiva. En el marco de un concepto histórico-filosófico global se aspira, haciendo referencia a la evolución en la India, donde Buda llegó a negar a los dioses, a un futuro ateo de Europa, criticándose el cristianismo por «habernos privado de los frutos de la cultura del islam» ya que "fue pisoteado el maravilloso mundo cultural moro de España». No obstante, desde mi punto de vista, el criterio de las críticas es, sobre todo en las obras tardías, la perspectiva afirmativa de la existencia: se aprecia, por ejemplo, a la cultura mora como una cultura que «dijo sí a la vida». De forma análoga se valora el mundo de los dioses de la cultura de la Edad Antigua. Incluso en el cristianismo, Nietzsche encuentra elementos considerados como positivos, por ejemplo, cuando habla de una «libertad meridional y de la liberalidad del espíritu» (FW $\$ 358, \mathrm{KGW}$ V/2 285) ${ }^{23}$.

Se trata, podemos decir en resumen, de un criterio de afirmación de la vida y de este mundo, según el cual se somete a valoración a las religiones y culturas del pasado y del presente; se trata, pues, de un «modelo de vida» del momento, tal y como se manifiesta en relación con Así habló Zaratustra. Dicha dimensión existencial se repite en figuras pertenecientes a la historia de la religión: Zaratustra y Dioniso son, probablemente, los «nombres» más significativos para la afirmación de la existencia en esa filosofía. En ese contexto cabe señalar que Nietzsche, en su formación académica, probablemente haya conocido esos nombres ya durante sus primeros años en la escuela media en Naumburg. En su libro de historia de aquella época encontramos subrayado el nombre del dios «Dionysus», hablándose en ese mismo libro además de Zoroastro y de su religión.

Esos nombres y su significado describen, asimismo, la relación de Nietzsche con las religiones y sus fundadores. A través de la filosofía de Nietzsche se determina, desde una nueva perspectiva, la relación entre una forma de pensar autónoma y las religiones tradicionales, produciéndose una «inversión» de la hermenéutica tradicional de textos y declaraciones religiosas: el sentido de la

23. Ibid., p. 346. 
existencia ya no se deduce partiendo de ellos, sino al contrario, es decir, el sentido de unos contenidos religiosos viene definido por el sujeto, por su elección y decisión. Esa situación puede interpretarse como el resultado de la percepción de la pluralidad de culturas y religiones en el siglo XIX. En mi opinión, Nietzsche ha tenido muy en cuenta esa nueva situación histórica en la que se encuentra el hombre de cultura europea, describiéndola en reiteradas ocasiones. De forma extremadamente precisa lo hace ya en su aforismo «Época de la comparación», publicado en Humano, demasiado humano I, una obra en la que algunos descubrimientos filológicos se convierten en el punto de partida para la definición de consecuencias filosóficas. En su aforismo n. ${ }^{\circ} 23$ dice:

[...] Semejante época trae su significación de que en ella las diversas concepciones del mundo, costumbres, civilizaciones, pueden compararse y vivirse unas junto a otras [...] iEs la época de la comparación! Es su orgullo, pero muy exactamente también su desgracia. iNo nos asustemos de esta desgracia! (KGW IV/2 40)24.

Ya que, debido a la relatividad y al devenir de todos los hechos religiosos y culturales, esos hechos ya no pueden ofrecer ninguna orientación fiable para la actuación del ser humano, la tarea existencial del hombre consiste, por consiguiente, en el descubrimiento individual del sentido de la existencia, es decir, no sólo en «encontrarlo» en textos y valoraciones transmitidos, sino en crearlo en el marco de una hermenéutica basada en la existencia, como dice Nietzsche a partir de «Zaratustra». Los conocimientos sobre religiones y culturas que Nietzsche ha ido adquiriendo a lo largo de su intensa trayectoria académica e investigadora, representan un telón de fondo permanente para su nueva filosofía, para su visión del ser humano y de las religiones y, finalmente, también para su posterior pretensión de superar en su totalidad la historia de la cultura y de la religión existente hasta el momento, en el sentido de un pensamiento profundamente transcultural.

[Traducción de Claudia Müller revisada por Luca Giancristofaro]

24. HH, trad. C. Vergara, Madrid-México: Edaf, 2003, p. 58. 